\title{
РАЗРАБОТКА ТРЕБОВАНИЙ ВСЕРОСИЙСКОГО ФИЗКУЛЬТУРНО-СПОРТИВНОГО КОМПЛЕКСА «ГОТОВ К ТРУДУ И ОБОРОНЕ» В ИСПЫТАНИИ «ТУРИСТСКИЙ ПОХОД С ПРОВЕРКОЙ ТУРИСТСКИХ НАВЫКОВ»
}

\section{DEVELOPMENT OF REQUIREMENTS OF THE ALL-RUSSIAN SPORTS COMPLEX «READY FOR WORK AND DEFENSE» IN THE TEST "TOURIST TRIP WITH A TEST OF TOURIST SKILLS»}

E. Veber

Summary: The article contains recommendations for the development of a program for passing the norms of the «VFSK» GTO «tourist route with a test of tourist skills», which are compiled within the established state requirements of the all-Russian sports complex «Ready for work and defense». The standards are developed taking into account the specific nature and requirements of safety, types of sports tourism (walking, water, skiing and (ycling) for each sign (bronze, silver and gold).

The historical development of «VFSK «GTO» in the test «tourist trip with a test of tourist skills» is considered. The analysis of the conditions existing earlier in the Soviet Union for obtaining the badge «Tourist of the USSR» is made. The standards for passing the relevant standards at the present stage and the development of appropriate methods are discussed.

Keywords: methodological developments, tourism, «Ready for work and defense» (TRP), categories of complexity, tourist routes.
Вебер Эльвина Павловна

Аспирант, Сургутский педагогический университет Trainer_2012@mail.ru

Аннотация: В статье приведены рекомендации по разработке программы для сдачи норм «ВФСК «ГТО» «туристский маршрут с проверкой туристских навыков», которые составлены в рамках установленных государственных требований Всероссийского физкультурно-спортивного комплекса «Готов к труду и обороне». Нормативы разработаны с учетом специфики характера и требований безопасности, видов спортивного туризма (пешеходный, водный, лыжный и велосипедный) для каждого знака (бронзового, серебряного и золотого).

Рассмотрено историческое развитие «ВФСК «ГТО» в испытании «туристский поход с проверкой туристских навыков». Сделан анализ существующих ранее в Советском Союзе условий для получения значка «Турист СССР». Обсуждаются нормативы для сдачи соответствующих норм на современном этапе и разработка соответствующих методик.

Ключевые слова: методические разработки, туризм, «Готов к труду и обороне» (ГТО), категории сложности, туристические маршруты.

(походных) условиях;

- ими осваивались навыки военно-прикладной направленности - воспитывалась выносливость, ориентирование на местности, умение преодолевать естественные преграды и препятствия, сооружать укрытия и проч.) [8].

Содержательно детско-юношеский туризм развивается в XX веке в виде составной части физической культуры и спорта, а также важнейшего компонента в духовно-нравственном и патриотическом воспитании детей, подростков и юношей.

И хотя четкого определения понятия «детско-юношеский туризм» нет, содержательно его можно определить как циклические занятия лиц школьного возраста, моложе 18 лет, педагогически целесообразно организованной деятельностью. Основная цель - физическое и интеллектуальное развитие личности; познание окружающего мира и самого себя; духовно-нравственное и 
патриотическое воспитание гражданина своей страны на основе участия в краеведческих исследованиях культуры этноса, национальных особенностей и традиций. Также в ходе проводимых занятий осваиваются социальные роли в межличностной коммуникации; видно профессиональное самоопределение посредством социально-профессиональных проб своих сил в системе должностно-ролевого походного туристско-краеведческого самоуправления; то есть происходит адаптация и социализация ребенка или подростка.

Сегодня детско-юношеский туризм рассматривают в виде мощного ресурса для системы образования, физической культуры и спорта. Не случайно, что в последнее время проблемы развития детско-юношеского туризма в современной России уделяют много внимания Президент, Правительство и Парламент РФ.

В возрожденный в 2014 году Президентом РФ В.В. Путиным Всероссийский физкультурно-спортивный комплекс «Готов к труду и обороне» (ГТО), благодаря в т. ч. усилиям общественности на стадии обсуждения, туризм включили как вид испытаний по выбору «Туристский поход с проверкой туристских навыков», хотя среди разработчиков данного комплекса было и до настоящего времени остается довольно много противников.

Здесь нужно отметить, что «Туристский поход с проверкой туристских навыков» как вид испытаний комплекса «ВФСК «ГТО» не есть инновацией, потому что содержательно отдельные элементы туризма изначально закладывались и присутствовали в определенной форме в испытаниях и нормативах ранее.

Так, первый символ по приобщению населения в СССР к туризму (в основном - молодежи и студенчества) - это значок «Турист СССР», решение про учреждение какого в 1935 году было принято Всесоюзным Комитетом по делам физкультуры и спорта при Совете Народных Комиссаров СССР. Чтобы получить такой значок юноша или девушка должны были сделать следующее:

- сдать нормы на значок «ГТО»;

- совершить туристское путешествие длительностью 6 и больше суток;

- уметь читать и ориентироваться по карте, компасу, солнцу, звездам, местным предметам, уметь организовать бивак (устанавливать палатку), разжигать костёр, приготавливать на нем пищу;

- знать правильный режим движения, как отдыхать, питаться и пить в походе;

- знать свой родной край;

- иметь элементарные знания по геологии и географии;

- уметь составлять отчет про свое путешествие.

При этом Положение про значок «Турист СССР» ут- вердил Всесоюзный Комитет по делам физкультуры при Совете Народных Комиссаров СССР только 26 марта 1939 года. Значок выдавали всем гражданам СССР, что достигли 18 лет, имели минимум 2 года туристского стажа и прошли не меньше 2-3 (в зависимости от трудности) походов. Кроме того, туристы должны представить не менее 1 отчета про путешествие и иметь соответствующие теоретические и практические знания по туризму в объеме специальной программы [8].

Безусловно, структура комплекса «ГТО» была тогда актуальной и прогрессивной. За время существования в СССР данного комплекса «ГТО» нормативная часть не раз изменялась. Самые существенные изменения комплекс ГТО претерпевал в 1940, 1947, 1955, 1965 и 1972 годах.

Также была разработана четкая методика выполнения норм «ГТО» по «туризму». Так, первый этап начальной подготовки включал в себя обязательное участие в походах выходного дня (ПВД). Цель этих небольших по протяженности однодневных туристских походов для школьников - сформировать представление про туризм, освоить умения и навыки, необходимые каждому человеку для того, чтобы успешно передвигаться и ориентироваться на местности, организовывать бивак и питание в походе. Нормативными были маршруты, протяженность каких возрастала в зависимости от возраста ребенка [7].

Дальнейшее совершенствование туристских умений и навыков достигалось в ходе регулярных занятий туризмом. В дальнейшем к сдаче нормативов на значок «Турист СССР» допускались лица, которые достигли 14-летнего возраста и имели на руках разрешение врача.

Нормативами на значок «Турист СССР» устанавливались требование совершить в течение 1 года одного или несколько походов, суммарная продолжительность которых была не меньше 5 дней и общая протяженность не менее 75 км. Такие требования были основой второго этапа начальной туристской подготовки и ими создавались условия для подготовки школьников и студентов к принятию участия в категорийных спортивных туристских походах.

При этом проверка знаний и навыков в туристском походе комплекса «ГТО» образца 1985 года включала в себя такие разделы:

- ориентирование на местности (открытой и в лесу) по карте и компасу;

- выбор места для разбивки бивака (лагеря);

- установка палатки;

- разжигание костра;

- приготовление пищи на костре;

- выбор способа преодолевать искусственные и 
естественные препятствия;

- умение оказать первую помощь при травмах и различных несчастных случаях.

Нужно отметить, что включение нормативов по туризму в комплекс ГТО было не случайным событием. В предшествующие годы спортивный туризм в СССР получил повсеместное распространение среди людей всех возрастов и профессий.

Возвращение системы ГТО - Всероссийского физкультурно-спортивного комплекса было реализовано на исполнение подпункта «а» пункта 1 перечня Поручений Президента Российской Федерации от 4 апреля 2013 г. № Пр-756. На основании Поручения Президента был издан приказ Минспорта России от 6 мая 2013 г. № 245 «О разработке проекта Всероссийского физкультурно-спортивного комплекса» (ВФСК), которым были определены 89 предприятий и вузов страны, в каких было проведено апробацию «пилотного» проекта массовых спортивных мероприятий по сдаче норм физкультурно-спортивного комплекса ДОСААФ России «Готов к труду и обороне» [8].

В 2014 году в комплекс «ВФСК «ГТО», который утвердило Минспортом РФ, включены тесты и нормативы для 11 групп (девочки и мальчики, девушки и юноши, женщины и мужчины), которыми охватывался возраст от 6 лет до пожилого возраста без ограничений его предела. Также в ВФСК включили выполнение норм по выбору «Туристский поход» в форме прохождения туристского похода. Нужно отметить, что такие нормативы были упрощены, если сравнивать их с предыдущими нормативными аналогами, содержащимися в нормах «ВФСК «ГТО». И нормативно-тестирующей частью комплекса предусматривается общая оценка уровня физической подготовленности, основываясь на выполнение нормативов, которыми характеризуются требования государства к состоянию физического здоровья российской нации.

На основе изложенного, можно разработать и сформировать следующие методические рекомендации и программу для сдачи норм «ВФСК «ГТО» по направлению «туристский маршрут с проверкой туристских навыков». Для этого был разработан Перечень туристских знаний и навыков, которые нужны для сдачи нормативов для детей и подростков от 12 до 17 лет (III, IV и V ступень). Охарактеризуем их детальнее.

\section{III ступень (6-7 к^ассы, 12-13 ^ет).}

1. Для сдачи норм «ВФСК «ГТО» в испытании «туристский маршрут с проверкой туристских навыков», обучающий должен знать:

- правила поведения в учебном классе, спортивном зале, на стадионе, учебно-тренировочном полигоне, экскурсиях и в туристском походе, при поездке в автобусе и поезде;

- обязанности всех членов группы в походе;

- требования к месту привала и бивака.

2. Для сдачи норм «ВФСК «ГТО» в испытании «туристский маршрут с проверкой туристских навыков», обучающий должен уметь:

1) подобрать личное снаряжение в соответствии с погодными условиями, уложить вещи в рюкзаке;

2) планировать бивак, ставить палатку;

3) строить (изготавливать) простые укрытия;

4) преодолевать естественные препятствия с организацией страховки и самостраховки: переправляться по веревках с перилами, подниматься и спускаться по склону по перилам с самостраховкой, переправляться по бревну с самостраховкой, используя перила, переправляться через овраг при помощи маятника;

5) вязать туристские узлы: «прямой», «встречный», «проводник», «восьмерка-проводник», «схватывающий», «удавка»;

6) измерять расстояния на карте и на местности;

7) двигаться по азимуту, используя компас, а также уметь сохранять заданное направление движения;

8) определять стороны горизонта по небесным светилам и местным предметам;

9) определять направления выхода при потере ориентировки;

10) обрабатывать раны, ссадины, порезы, мозоли; оказывать первую помощь при отравлении, при укусах насекомых, змей, при ушибах и проч.[8].

\section{IV ступень (8-9 классы,14-15 ^ет).}

1. Для сдачи норм «ВФСК «ГТО» в испытании «туристский маршрут с проверкой туристских навыков», обучающий должен знать порядок действий, когда:

- возникают опасные природные явления и стихийные бедствия;

- он теряет ориентировку или отстает от группы;

- травмируется или заболевает участник похода.

2. Для сдачи норм «ВФСК «ГТО» в испытании «туристский маршрут с проверкой туристких навыков», обучающий должен уметь:

1) разводить костёр в сложных условиях;

2) преодолевать препятствия на маршруте;

3) изготавливать временные укрытия;

4) участвовать в туристских личных и командных соревнованиях;

5) двигаться по легенде, по маркированной трассе, по выбору в заданном направлении;

6) определять стороны света без компаса;

7) участвовать в соревнованиях по ориентирова- 
нию;

8) выбирать оптимальный маршрут, двигаясь по разных участках местности;

9) оказывать первую помощь при отравлениях, когда случились ушибы, растяжения, вывихи, травмы головы, позвоночника или спины;

10) изготавливать определенные транспортировочные средства и транспортировать «пострадавшего».

\section{V ступень (10-11 классы, 16-17 ^ет)}

1. Для сдачи норм «ВФСК «ГТО» в испытании «туристский маршрут с проверкой туристских навыков», обучающий должен знать:

- порядок действий, если организовываются поисково-спасательные работы силами группы для поиска отставших или заблудившихся членов группы;

- порядок действий при поиске члена группы, который потерял ориентировку или отстал от группы;

- порядок действий, когда член группы травмировался или заболел в походе.

2. Для сдачи норм «ВФСК «ГТО» в испытании «туристский маршрут с проверкой туристких навыков», ученик должен уметь:

1) составлять план подготовки похода;

2) составлять план-график движения;

3) выполнять обязанности судьи этапа на туристских соревнованиях;

4) проходить индивидуально и в составе группы дистанции соревнований по туризму;

5) вести группу по разработанному маршруту;
6) корректировать проходимый маршрут;

7) участвовать в соревнованиях по спортивному ориентированию;

8) оказывать первую помощь при травмах головы и позвоночника;

9) проводить непрямой массаж сердца;

10)осуществлять искусственную вентиляцию лёгких [5].

При этом предлагается жесткая регламентация нормативов по конкретным туристским навыкам: установка палатки, туристское ориентирование, разведение костра без учета заготовки дров; преодоление препятствий на маршруте без регламентации времени, однако с регламентацией общего их количества (табл. 1).

При этом при приеме норматива для III-VI ступеней обязательно нужно проводить проверку туристских навыков, которая можно проводить непосредственно в Центре туризма, при прохождении маршрута, или во время участия в туристских слетах и соревнованиях.

В каждой ступени тестируемому нужно продемонстрировать умение владеть туристскими навыками, каждый из каких должен оцениваться по следующей системе:

$$
\begin{aligned}
& \text { - прием выполнен правильно - } 2 \text { балла; } \\
& \text { - прием выполнен с ошибками - } 1 \text { балл; } \\
& \text { - прием не выполнен - } 0 \text { баллов. }
\end{aligned}
$$

Также в каждой из III-VI ступеней для зачета на бронзовый знак нужно будет продемонстрировать владение не менее 3 навыками (3-6 баллов), для зачета на серебряный знак - не менее 5 навыками (7-10 баллов), для

\begin{tabular}{|c|c|c|c|c|c|}
\hline $\begin{array}{l}\text { № } \\
\text { п/п }\end{array}$ & Виды испытаний & Ступень & Бронзовый знак & Серебряный знак & Золотой знак \\
\hline \multirow[t]{3}{*}{1} & \multirow{3}{*}{$\begin{array}{l}\text { Установка палатки (группа } \\
\text { состоит из 4-5 человек) }\end{array}$} & III ступень & 15 мин & 12 мин & 10 мин \\
\hline & & IV, V, IX ступень & 10 мин & 8 мин & 5 мин \\
\hline & & VI, VII, VIII ступени & 5 мин & 4 мин & 3 мин \\
\hline \multirow[t]{3}{*}{2} & \multirow{3}{*}{$\begin{array}{l}\text { Туристское ориентирование. } \\
\text { Определение азимута на } \\
\text { предмет }\end{array}$} & III ступень & 2 мин (откл. до 25잉 & 1 мин (откл. до 20) & 30 сек (откл. до 15) \\
\hline & & IV, V, IX ступень & (отклонение до 20) & (отклонение до 15²) & (отклонение до $10^{\circ}$ ) \\
\hline & & VI, VII, VIII ступени & (отклонение до 15) & (отклонение до 10) & (отклонение до 5) \\
\hline \multirow[t]{3}{*}{3} & \multirow{3}{*}{$\begin{array}{l}\text { Преодоления определенных } \\
\text { препятствий (по выбору судьи } \\
\text { похода или организатора) }\end{array}$} & III ступень & два препятствия & три препятствия & четыре препятствия \\
\hline & & IV, V, IX ступень & три препятствия & четыре препятствия & пять препятствий \\
\hline & & VI, VII, VIII ступени & четыре препятствия & пять препятствий & шесть препятствий \\
\hline \multirow[t]{3}{*}{4} & \multirow{3}{*}{$\begin{array}{l}\text { Разведение костра без учета } \\
\text { заготовки дров }\end{array}$} & III ступень & 15 мин & 12 мин & 10 мин \\
\hline & & IV, V, IX ступень & 10 мин & 8 мин & 6 мин \\
\hline & & VI, VII, VIII ступени & 8 мин & 5 мин & 3 мин \\
\hline
\end{tabular}

Таблица 1.

Пример методики сдачи норм «ВФСК «ГТО «туристский поход с проверкой туристских навыков» 
зачета на золотой знак - не менее 7 навыками (более 11 баллов) [4].

Навыки должны проверяться практическим путем при выполнении заданий и преодолении естественных препятствий на маршруте во время проведения турпохода, во время туристских слетов и соревнований. В центрах туризма лучше всего проверять такие навыки посредством туристской полосы препятствий, включая в такие этапы различные задания.

Также проверку туристских навыков можно осуществлять в ходе проведения туристских слетов и соревнований, смотров готовности, туриад и прочих массовых мероприятий, которые традиционно проводятся в многих регионах нашей страны и в каких принимают участие представители центров туризма. В основном, к месту проведения слета участники должны пройти определенное количество километров, принять участие в определенных туристских соревнованиях и конкурсах.

Набор этапов должен определяться исходя из опыта участников, учитывая местные условия, подготовленность судей и т.д. При этом участие может быть, как индивидуальным, так и в составе группы.

В методических рекомендациях очень важно отметить, что в походе важна роль руководителя группы, который должен ознакомиться с особенностями маршрута, подготовить картографический материал, правильно заполнить походную документацию. Перед выходом на маршрут ему нужно провести инструктаж, в каком обязательно осветить следующие вопросы:

- сведения про предстоящий маршрут;

- экипировку участников;

- четкие правила пользования туристским снаряжением;

- основные приемы передвижения и ориентирования на местности и преодолении естественных препятствий.

Особенно внимательным следует быть при движении по сложным участкам местности - крутые склоны, мокрые камни на берегах рек, на переправах через их, двигаясь по болоту и т. д. Важно быть осторожным у разведенного костра, не пить воду из неизвестных источни- ков и проч.

Таким образом, можно подытожить, что спортивно-туристскую деятельность сегодня по праву считают самым массовым, доступным и эмоционально привлекательным видом самореализации человека в спорте. Общие цели в спортивном туризме - достигать спортивные результаты, физически и нравственно развиваться и успешно сдать нормы «ВФСК «ГТО». Комплекс «ВФСК «ГТО» состоит из 11 ступеней в соответствии с возрастными группами населения от 6 до 70 лет и старше и нормативов по 3 уровням трудности, которые, как отмечалось, соответствуют золотому, серебряному и бронзовому знакам.

Поэтому одна из важных функций туризма - сформировать всестороннюю и гармонически развитую личность. На занятиях, в тренировочных и походных условиях воспитываются волевые качества в виде смелости и решительности, терпеливость, настойчивость, инициативность, дисциплинированности. Всестороннее воспитание волевых качеств должно входить в основное содержание подготовки будущих туристов [8].

При этом подготовка учащейся молодежи к успешной сдаче нормативов комплекса «ВФСК «ГТО» по направлению «туристский маршрут с проверкой туристских навыков» на основе реализации разработанной методики, основанной на участиях в туристических походах, предоставляет юношам и девушкам дополнительные возможности для выполнения нормативов на золотой, серебряный или бронзовый знак отличия по туризму.

И это не случайно, так как туристский поход с проверкой туристских навыков - очень интересный вид испытания комплекса «ВФСК «ГТО» В направлении «туристский маршрут с проверкой туристских навыков». В нем нужно не только пройти определенную дистанцию, но и научится ставить палатки, правильно упаковывать рюкзак, вязать различные узлы, ориентироваться на местности, разжигать костер и т.д. поэтому разработанная методика будет способствовать центрам тестирования в нашей стране более качественно проводить работу в данном направлении, а полученные результаты сделать более точными.

\section{ЛИТЕРАТУРА}

1. Бариев М.М. Становление и развитие комплекса ГТО в СССР и современной России. / М.М. Бариев, Р.А. Юсупов, В.М. Ермолаев. // Теория и практика физической культуры, 2016. - № 2. - С. 94-96.

2. Добрынин И.М. Подготовка комплекса мер, направленных на выполнение нормативов ГТО в вузе: учебное пособие. / И.М. Добрынин, В.А. Шемятихин. - Екатеринбург: Издательство Уральского университета, 2016. - 99 с.

3. Клюшникова Е.А. Туризм в комплекте ГТО. / Е.А. Клюшникова. // Вестник академии детско-юношеского туризма и краеведения, 2017. - № 30 (143). C. $25-30$. 
4. Константинов Ю.С. Методические рекомендации по выполнению нормативов испытания (теста) «туристический поход» Всероссийского физкультурноспортивного комплекса «Готов к труду и обороне» (ГТО). / Ю.С. Константинов. // Вестник академии детско-юношеского туризма и краеведения, 2017. № 28 (141). - C. 35-45.

5. Насонова Н.Ю. Формирование туристических навыков как средство физического воспитания детей для успешной сдачи норм ГТО. / Н.Ю. Насонова. // Современные инновации, 2017. - № 1 (15). - С. 79-81.

6. Перова Е.И. Опыт апробации и внедрения комплекса ГТО в различных регионах Россиийской Федерации. / Е.И. Перова. // Физическая культура в школе, 2015. - № 7. - C. 47-55.

7. Скок Н.В., Янцер 0.В. Туристская подготовка школьников при реализации программы Всероссийского физкультурно-спортивного комплекса. / Н.В. Скок, 0.В. Янцер. // Актуальные проблемы внедрения Всероссийского физкультурно-спортивного комплекса «Готов к труду и обороне» (ГТ0) в системе образования // Педагогическое образование в России, 2014. - № 9. - С. 93-98.

8. Смирнов А.А., Смирнов Д.В. Содержание и нормативные требования к туристскому походу во всероссийском физкультурно-спортивном комплексе «Готов к труду и обороне». / А.А. Смирнов, Д.В. Смирнов. // Вестник академии детско-юношеского туризма и краеведения,2015. - № 3 (116). - С. $25-63$.

9. Спирин В.К. Нормативная база Всероссийского физкультурно-спортивного комплекса в качестве условия обоснования технологии подготовки и организации сдачи норм ГТО. / В.К. Спирин, В.А. Багина, А.А. Степанов. // Физическая культура: воспитание, образование, тренировка, 2015. - № 1. - С. 2-6.

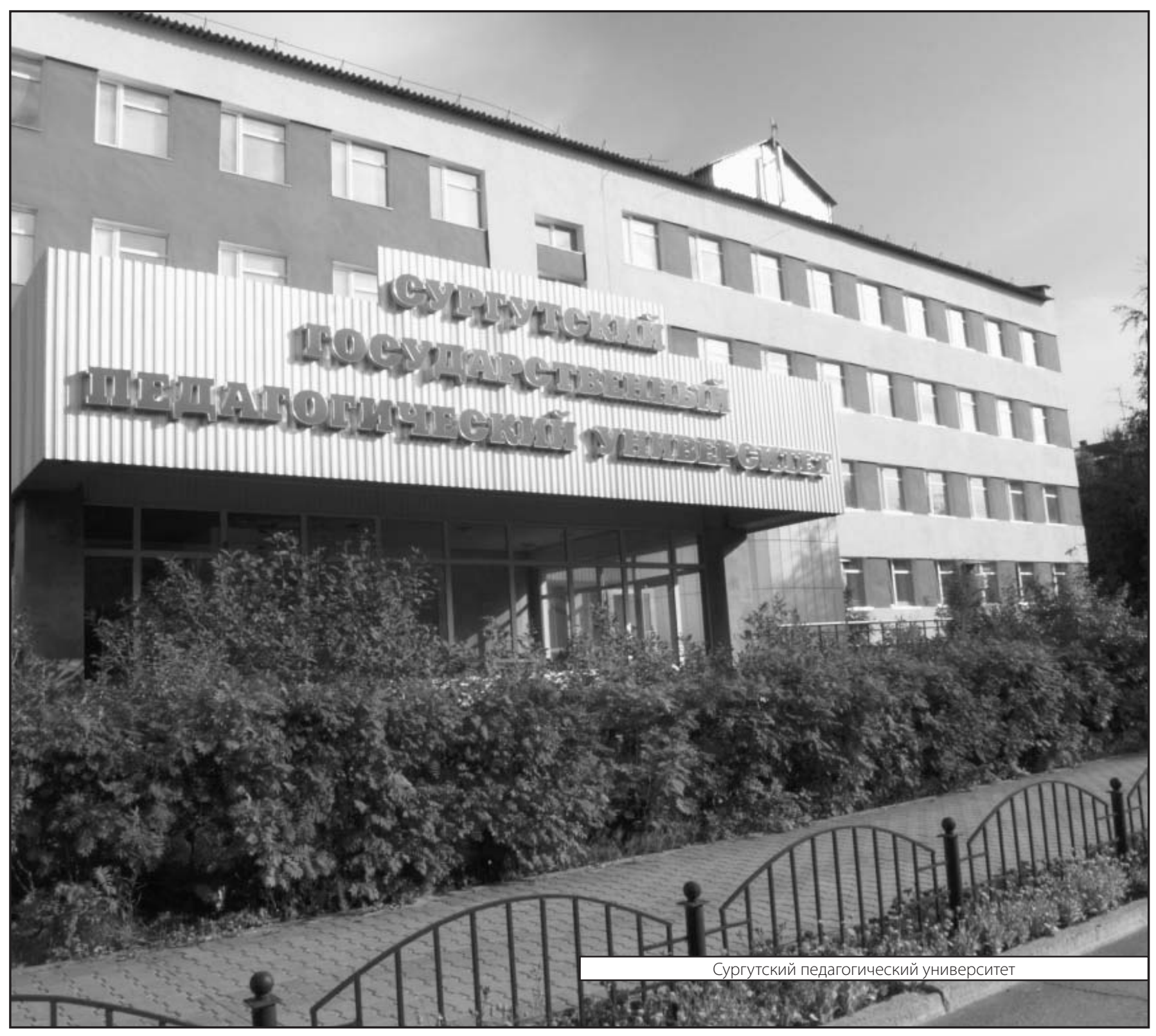

